\title{
Validity and Reliability of the Turkish version of DSM-5 Social Anxiety Disorder Severity Scale- Child Form
}

\author{
Şermin YALIN SAPMAZ' (D), Dilek ERGIN² (D), Nesrin ŞEN CELASIN² (D), Duygu KARAARSLAN ${ }^{2}$ (D) \\ Masum ÖZTÜRK' (D, Handan ÖZEK ERKURAN ${ }^{3}$ (D), Ertuğrul KÖROĞLU ${ }^{4}$ (D), Ömer AYDEMIR ${ }^{5}$ (D)
}

\author{
'Department of Child and Adolescent Psychiatry, Manisa Celal Bayar University School of Medicine, Manisa, Turkey \\ 2Department of Pediatric Nursing, Manisa Celal Bayar University School of Health, Manisa, Turkey \\ ${ }^{3}$ Department of Child and Adolescent Psychiatry, Dr. Behçet Uz Childrens Hospital, İzmir, Turkey \\ ${ }^{4}$ Boylam Psychiatry Hospital, Ankara, Turkey \\ ${ }^{5}$ Department of Psychiatry, Manisa Celal Bayar University School of Medicine, Manisa, Turkey
}

\section{ABSTRACT}

Introduction: This study aimed to assess the validity and reliability of the Turkish version of the Diagnostic and statistical manual of Mental Disorders. ( $5^{\text {th }}$ ed.) (DSM-5) Social Anxiety Disorder Severity ScaleChild Form.

Method: The scale was prepared by carrying out the translation and back translation of the DSM-5 Social Anxiety Disorder Severity Scale - Child Form. The study group consisted of 31 patients that had been treated in a child psychiatry unit and diagnosed with social anxiety disorder and 99 healthy volunteers that were attending middle or high school during the study period. For the assessment, the Screen for Child Anxiety and Related Emotional Disorders (SCARED) was also used along with the DSM-5 Social Anxiety Disorder Severity Scale Child Form
Results: Regarding reliability analyses, Cronbach's alpha internal consistency coefficient was calculated as 0.941 , while item-total score correlation coefficients were measured between 0.566 and 0.866 . A test-retest correlation coefficient was calculated as $r=0.7 \mathrm{I}$ I. As for construct validity, one factor that could explain $66.0 \%$ of the variance was obtained. As for concurrent validity, the scale showed a high correlation with the SCARED.

Conclusion: It was concluded that the Turkish version of the DSM-5 Social Anxiety Disorder Severity Scale - Child Form could be utilized as a valid and reliable tool both in clinical practice and for research purposes.

Keywords: DSM-5, Social Anxiety Disorder Severity Scale, reliability, validity

Cite this article as: Yalın Sapmaz Ş, Ergin D, Şen Celasin N, Karaarslan D, Öztürk M, Özek Erkuran H, Köroğlu E, Aydemir Ö. Validity and Reliability of the Turkish version of DSM-5 Social Anxiety Disorder Severity Scale- Child Form. Arch Neuropsychiatry 20 I7; 54:354-357.

\section{INTRODUCTION}

Social anxiety disorder (SAD) is a clinical phenomenon where the individual has prominent fear or anxiety in single or multiple social situations such as in social interactions, when being watched, or performing an act in front of other people. The individual fears of acting in a way that would make him/her regarded in a negative way or showing symptoms about his/her anxiety in abovementioned situations. These social situations are avoided or the individual bears them with intense fear and anxiety (I).

Social anxiety disorder is among the most common psychiatric disorders seen in the general population. One out of 10 individuals is diagnosed with this disorder at some time during their lives before they reach early adulthood (2). The onset of the disorder is typically in childhood or early adolescence. The diagnosis of SAD during this developmental phase is related to feelings of loneliness, dysphoria, poor social activities, nicotine use and increased peer abuse $(3,4)$. In a study where the sample consisted of 20 I individuals diagnosed primarily with anxiety disorders, the most common sub-diagnosis was SAD and it was striking that $50 \%$ of the individuals within this group had left school early. The two most common reasons for dropping out of school were speaking out/taking a word in front of the class and the distress/anxiety caused by this situation (5).

To assess social anxiety in children and adolescents, clinicians might benefit from using structured or semistructured clinical interviews, assessments based on observation and self-report forms. There are self-report scales that have been prepared specifically for children and adolescents and scales that measure anxiety, fear, social competence and skills in general. The Social Anxiety Scale for Children- Revised, the Social Anxiety for Adolescents (SAS-A) and the Social Phobia and Anxiety Scale for Children are commonly used self-report scales within this field (6).

With the publication of the Diagnostic and statistical manual of Mental Disorders. (5 $5^{\text {th }}$ ed.) (DSM-5) Diagnostic Criteria in 20 I3, new scales and tools were required to determine the severity of the disorders and to follow-up for both field studies and for current psychiatric services,

Correspondence Address: Şermin Yalın Sapmaz, Manisa Celal Bayar Universitesi Tıp Fakültesi, Çocuk Ergen Ruh Sağlığı ve Hastalıkları

Anabilim Dalı, Manisa, Türkiye E-mail: drserminyalin@hotmail.com

Received: 19.03.2016 Accepted: 23.07.2016

(c) Copyright 2017 by Turkish Association of Neuropsychiatry - Available online at www.noropskiyatriarsivi.com 
creating a space for the recommendation of new assessment tools that are based on DSM-5 criteria for many psychiatric disorders (7).

The DSM-5 Social Anxiety Disorder Severity Scale - Child Form assesses the severity of social anxiety symptoms in children and adolescents aged between II and 17 years. It was designed to be utilized during the first assessment and through follow-up in individuals diagnosed with SAD (or that have clinically severe social anxiety) (7). It is the first scale based on the DSM-5 diagnostic classification.

This study aimed to assess the validity and reliability of the Turkish version of the DSM-5 Social Anxiety Severity Scale - Child Form.

\section{METHOD}

\section{Translation Process}

To carry out the adaptation of the DSM-5 Social Anxiety Severity Scale Child Form into Turkish, written consent was firstly obtained from HYB Yayıncılık and Boylam Psikiyatri Enstitüsü who held the publication and translation rights for the DSM-5 Source Book and Handbook for scale studies. The translation was carried out by three child and adolescent psychiatry specialists. When the text was controlled and agreed upon, it was translated into English. The translated text was compared to the original and was checked if it met the warranted criteria for the inclusion of expected concepts. When the necessary approval was obtained, the scale text was finalized.

\section{Sample Group}

Healthy volunteers and patients that had been followed up in Manise Celal Bayar University Child Psychiatry Outpatient Unit were included in the sample. The clinical sample representing the high-risk group regarding psychiatric symptoms consisted of 31 adolescents aged between $\mid \mathrm{I}$ and 17 years that had been followed up in CBÜ Medical School Child Psychiatry Outpatient Unit with a diagnosis of SAD according to the DSM-5 criteria. Diagnoses in the patient group were made by carrying out clinical interviews based on the DSM- 5 diagnostic classification system. Inclusion criteria were being $11-17$ years of age, meeting the criteria for SAD according to the DSM-5 and having the intellectual capacity to follow the instructions of the study. Exclusion criteria were having a physical or a neurological disorder that would require continuous treatment. The community sample representing the low-risk group psychiatrically was collected from schools in the catchment area. To obtain a sufficiently large sample, the study group needed to include a number of volunteers that would be 5 - 10 fold the number for the scale's number of the items, in general, based on research statistics. For this reason, the number of students in the healthy group was determined as 100 and it was possible to contact 99 healthy volunteers. Inclusion criteria for the control group were being 1 | -17 years of age, not meeting any criteria for a psychiatric or a physical disorder and having the intellectual capacity to follow the study instructions.

Ethical approval was given by Manisa Celal Bayar University Medical School Clinical Researches Evaluation Committee.

\section{Assessment Tools}

I. The DSM-5 Social Anxiety Disorder Severity Scale - Child Form is a scale with 10 items that measure the severity of social anxiety in children and adolescents aged $1 \mathrm{I}-17$ years. The scale was designed to be used in the first assessment and follow-up of children and adolescents with social anxiety (or those with severe clinical social anxiety symptoms). For each item, the individual is asked to rate the severity of specific phobia within the last 7 days. Total scores vary between 0 and 40, with higher score reflecting more severe social anxiety. In a study conducted with a community sample that consisted of children aged 8-13 years in the Netherlands, the scale was shown to be a valid and reliable tool (8).

2. The Screen for Child Anxiety and Related Disorders (SCARED) scale was developed by Birmaher et al. (9) to screen for anxiety disorders in childhood. The SCARED has a parent and child form and a Turkish validity and reliability study was completed by Çakmakçı et al. (10) in 2004. The SCARED consists of $4 \mathrm{I}$ items in total and scores of 25 and above indicate a warning for anxiety disorders. The scale also has subscales for somatic/ panic, generalized anxiety, separation anxiety, social anxiety, and school anxiety.

\section{Statistical Analysis}

For statistical analysis, to show that there were no statistically significant differences between the study groups regarding sociodemographic and clinical features, independent samples t-tests were applied to the numeric variables, while chi-square test to categorical variables. Correlation analyses between the parameters were conducted with Pearson's correlation analysis. The level of significance was determined at $p \leq 0.05$. For all the means subjected to the statistical analyses, normal distribution was tested with Levene's test and all means were found to be normally distributed.

For reliability analysis, Cronbach's alpha internal reliability analysis was performed. The reliability of the scale was determined by measuring item-total score correlation coefficients. For the study, the DSM-5 Social Anxiety Disorder Severity Scale was reapplied to 42 healthy volunteers 2 weeks after the initial application and test-retest reliability was determined by calculating the correlation coefficient between the two consecutive applications.

For construct validity of the scale, explanatory factor analysis was applied by using data derived from all study groups. Firstly, to control the congruity of the sample for explanatory factor analysis, the Kaiser-Meier-Olkin Test and Bartlett's Test were used. Explanatory factor analysis was carried out by applying varimax rotation according to main compounds method and factors with eigenvalues equal to $I$ and above were included in the analysis. Among factor constructs, items with factor loads of 0.4 and above were included in the analysis. The explanatory factor construct was compared to the original dimension structure of the scale. Regarding concurrent validity, the correlation between the DSM-5 Social Anxiety Disorder Severity Scale Child Form and the SCARED was measured.

\section{RESULTS}

The study was conducted with $3 \mathrm{I}$ patients that had applied to the Manisa Celal Bayar Üniversitesi Child Psychiatry Unit and had been diagnosed with SAD and 99 healthy volunteers. Sociodemographic and clinical features of study groups are shown in Table I.

Significant differences between the patient group and the control group were found for gender $\left(\chi^{2}=7.159, p=0.007\right)$, mother's educational status $\left(\chi^{2}=60.678, p<0.000 \mathrm{I}\right)$, father's educational status $\left(\chi^{2}=47.464\right.$, $p<0.0001)$, the DSM-5 Social Anxiety Disorder Severity Scale Child Form's total score $(t=-8.882, p<0.0001)$, the SCARED Social Anxiety Subscale total score $(t=-7.49 \mathrm{I}, \mathrm{p}<0.000 \mathrm{I})$, and the SCARED total scores $(t=-8.100, p<0.0001)$. 


\section{Reliability Analyses}

Cronbach's alpha internal consistency coefficient was measured as 0.941 in the reliability analysis for the DSM-5 Social Anxiety Disorder Severity Scale Child Form. Cronbach's alpha coefficients for each item are shown

Table I. Sociodemographic data of the study group

\begin{tabular}{|c|c|c|c|}
\hline Parameters & & $\begin{array}{c}\text { Social anxiety } \\
\text { disorder group } \\
\mathbf{N}: 3 \mathbf{I}\end{array}$ & $\begin{array}{l}\text { Control } \\
\text { group } \\
\text { N: } 99\end{array}$ \\
\hline Age & & $15.06 \pm 1.87$ & $15.72 \pm 1.08$ \\
\hline \multirow[t]{2}{*}{ Gender* } & Female & $22(71.0 \%)$ & $42(42.4 \%)$ \\
\hline & Male & $9(29.0 \%)$ & $57(57.6 \%)$ \\
\hline \multirow[t]{2}{*}{ Academic status } & Attending & $31(100 \%)$ & 99 (100\%) \\
\hline & Not attending & $0(0 \%)$ & $0(0 \%)$ \\
\hline \multirow[t]{3}{*}{$\begin{array}{l}\text { Mother's educational } \\
\text { status* }\end{array}$} & $\begin{array}{l}\text { Primary and } \\
\text { secondary school }\end{array}$ & $18(58.1 \%)$ & $2(2 \%)$ \\
\hline & High school & 8 (25.8\%) & 25 (25.3\%) \\
\hline & College & $5(16.1 \%)$ & 72 (72.7\%) \\
\hline \multirow[t]{3}{*}{$\begin{array}{l}\text { Father's educational } \\
\text { status* }\end{array}$} & $\begin{array}{l}\text { Primary and } \\
\text { secondary school }\end{array}$ & $14(45.2 \%)$ & $2(2 \%)$ \\
\hline & High school & $10(32.3 \%)$ & $21(21.2 \%)$ \\
\hline & College & $7(22.6 \%)$ & $76(76.8 \%)$ \\
\hline \multirow{3}{*}{$\begin{array}{l}\text { Duration of the } \\
\text { disorder }\end{array}$} & New diagnosis & $0(0 \%)$ & $0(0 \%)$ \\
\hline & I-6 months & $31(100 \%)$ & $0(0 \%)$ \\
\hline & $\begin{array}{l}\text { More than } 6 \\
\text { months }\end{array}$ & $0(0 \%)$ & $0(0 \%)$ \\
\hline \multirow[t]{3}{*}{ Medication use } & Antidepressants & $31(100 \%)$ & $0(0 \%)$ \\
\hline & Antipsychotics & $4(12.9 \%)$ & $0(0 \%)$ \\
\hline & Benzodiazepines & $0(0 \%)$ & $0(0 \%)$ \\
\hline \multirow[t]{3}{*}{$\begin{array}{l}\text { Scores of the scales } \\
\text { applied* }\end{array}$} & $\begin{array}{l}\text { DSM-5 Social } \\
\text { Anxiety Disorder } \\
\text { Severity Scale* }\end{array}$ & $20.67 \pm 9.1$ & $4.8 \pm 6.8$ \\
\hline & $\begin{array}{l}\text { SCARED Social } \\
\text { Anxiety Subscale* }\end{array}$ & $11.3 \pm 3.2$ & $4.9 \pm 4.3$ \\
\hline & SCARED * & $46.7 \pm 15.5$ & $21.9 \pm 13.9$ \\
\hline
\end{tabular}

in Table 2. Item-total score correlation coefficients were found to be between 0.566 and 0.866 (Table 2). Data for 42 volunteers were used to assess test-retest reliability and the correlation coefficient between the two applications (two weeks apart) was $r=0.7$ I I $(p<0.000$ I).

\section{Validity Analyses}

To determine construct validity, explanatory factor analysis was applied to the DSM-5 Social Anxiety Disorder Severity Scale Child Form. Before the application of explanatory factor analysis, a Kaiser-Meyer-Olkin analysis was completed to assess whether the sample was in congruity indicated a coefficient value of 0.902. By using Bartlett's test, a chi-square value was calculated as 1053.1 I 4 ( $p<0.000$ I). These results indicate that the sample group is in congruity with factor analysis.

In factor analysis, one factor with an eigenvalue above I was maintained; the eigenfactor value was 6.602 and explained $66.0 \%$ of the variance.

In the concurrent validity analysis for the DSM-5 Social Anxiety Disorder Severity Scale Child Form and the SCARED, the correlation coefficient was found to be $r=0.730 p<0.000$ I for the total score of the scale while $r=0.622 p<0.000$ I for social anxiety subscale.

\section{DISCUSSION}

This study explored the validity and reliability of a Turkish version of the DSM-5 Social Anxiety Disorder Severity Scale Child Form and showed that the Turkish version was applicable.

In the original development of the scale, in a reliability study with a child group, Cronbach's alpha coefficient was found to be 0.84 (8). Cronbach's alpha coefficient in our study was found to be 0.941 , which could be regarded as a high value and might also indicate that the scale could appropriately represent its construct as a whole. Item-total score correlation coefficients were also found to be high and suggest that the construct is reliable. The correlation coefficient between the two applications as a result of test-retest application was found to be $r=0.8 \mathrm{I}$ in the adult population study of the scale's original development phase $(\mathrm{I} \mathrm{I})$. In our study, the correlation coefficient was $r=0.7 \mathrm{I} \mathrm{I}$, which is a high value and statistically significant. All these results indicate that the scale could be used as a reliable tool.

In the concurrent validity analysis, the correlation coefficient between the Social Anxiety Disorder Severity Scale and the SCARED's social anxiety

Table 2. Item-total score correlation coefficients, Cronbach's alpha coefficients, factor loads for items of the Social Anxiety Disorder Severity Scale Child Form

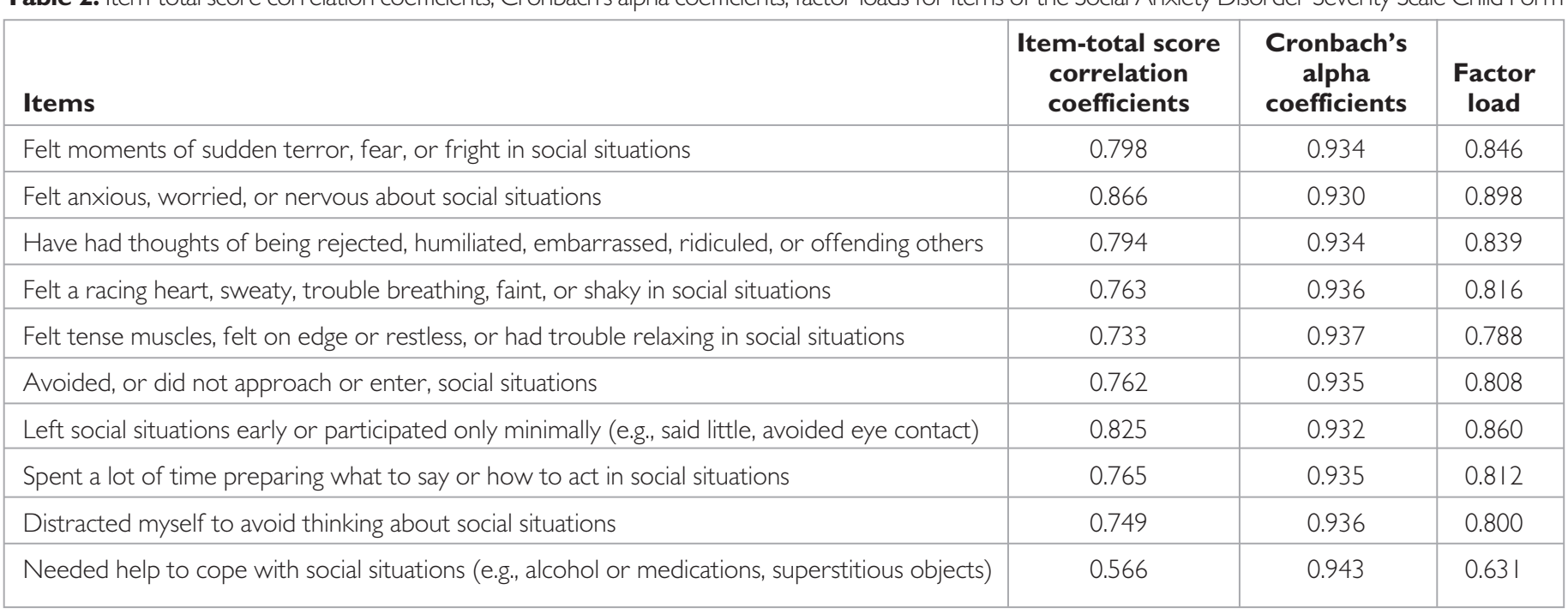


subscale was calculated. In the first study conducted in children, correlation with the social anxiety subscale was measured and coefficient was found to be 0.59 (8). In our study, correlation coefficient with SCARED's social anxiety subscale was found to be $r=0.622$, which indicates a medium-level correlation and with SCARED total scores as $r=0.730$, which indicates a high level of correlation. When both scales are evaluated, it can be seen that avoidance behavior in social situations and somatic symptoms that appear in social contexts do not take place in the SCARED's social anxiety subscale. This might be the reason why there was a relatively low correlation coefficient in concurrent validity and also might have caused an increase in the correlation coefficient with the total scores due to the presence of somatic symptoms within the SCARED's other subscales. A group consisting of patients with any anxiety disorder, not specifically social anxiety, might have also yielded higher levels of correlation with the total score of the scale. Concurrent validity of the scale supports the possibility of using the scale in a valid way.

Explanatory factor analysis was applied to the DSM-5 Social Anxiety Disorder Severity Scale. In our study, one factor with an eigenvalue over I was obtained. The eigenfactor value of the first factor was 6.602 and it explained $66.0 \%$ of total variance and was in congruity with the original construct of the scale (12).

Both the construct validity and concurrent validity indicate that the scale might be used as a valid tool.

\section{Limitations and advantages of the study}

A primary limitation to this study was the relatively low number of the sample group where the patients would have to be consisted of individuals within the symptomatic phase. Another limitation was the lack of a structured clinical interview for the control group to determine diagnoses. In the meantime, the presence of a significant difference between patient and control groups regarding gender, education and parental education statuses has to be taken into consideration when evaluating differences obtained in comparative analyses for items of the scale. In the directory of the study aims, all statistical analyses could be carried out without any outage in the sample with the given size. A strength of this study might be the sample size being representative of patients; this supports the clinical utility of the scale.

These findings indicate that the Turkish Form of the DSM-5 Social Anxiety Disorder Severity Scale Child Form could be used as a valid and reliable tool in clinical practice and for research purposes.

Ethics Committee Approval: Ethics committee approval was received for this study from the ethics committee of (No: 19.1 1.2014/20478486-377).
Informed Consent: Written informed consent was obtained from child' parents who participated in this study.

Peer-review: Externally peer-reviewed.

Author Contributions: Concept - O.A., E.K., Ş.Y.S.; Design - O.A., E.K., Ş.Y.S.; Supervision - O.A., S.Y.S., E.K.; Data Collection and/or Processing - H.O.E., D.E., N.Ş.C., D.K., M.O.; Analysis and/or Interpretation - O.A., S.Y.S., H.O.E.; Literature Search - D.E., N.Ş.C., D.K., M.O.; Writing - Ş.Y.S., H.O.E., M.O., D.E., N.Ş.C., D.K.; Critical Reviews - O.A.

Conflict of Interest: No conflict of interest was declared by the authors.

Financial Disclosure: The authors declared that this study has received no financial support.

\section{REFERENCES}

I. American Psychiatric Association. Diagnostic and statistical manual of Mental Disorders. (5th ed.). Washington D.C: American Psychiatric Association; 2013.

2. Burstein M, He JP, Kattan G, Albano AM, Avenevoli S, Merikangas KR. Social phobia and subtypes in the National Comorbidity Survey-Adolescent Supplement: prevalence, correlates, and comorbidity. J Am Acad Child Adolesc Psychiatry 201 I; 50:870-880. [CrossRef]

3. Storch EA, Masia-Warner C, Crisp H, Klein RG. Peer victimization and social anxiety in adolescence: a prospective study. Aggressive Behav 2005; $31: 437-452$. [CrossRef]

4. Wu P, Goodwin R, Fuller C, Liu X, Comer JS, Cohen P, Hoven CW. The relationship between anxiety disorders and substance use among adolescents in the community: specificity and gender differences. J Youth Adolesc 20 I0; 39:177- | 88. [CrossRef]

5. Van Ameringen M, Mancini C, Farvolden P. The impact of anxiety disorders on educational achievement. J Anxiety Disord 2003; 17:561-5706. [CrossRef]

6. Tulbure BT, Szentagotai A, Dobrean A, David D. Child Psychiatry Hum Dev Evidence Based Clinical Assessment of Child and Adolescent Social Phobia: A Critical Review of Rating Scales 20 12; 43:795-820.

7. http://www.psychiatry.org/practice/dsm/dsm5/online-assessment-measures.

8. Möller EL, Majdandzic M, Craske MG, Bögels SM. Dimensional assessment of anxiety disorders in parents and children for DSM-5Int. J. Methods Psychiatr Res 20I4; 23:33I-344. [CrossRef]

9. Birmaher B, Brent DA, Chiapetta L, Bridge J, Monga S, Baugher M. Psychometric properties of the screen for Child Anxiety Related Emotional Disorders (SCARED): A replication study. J Am Acad Child Adolesc Psychiatry 1999; 38:1230-1236. [CrossRef]

10. Çakmakç FK. Reliability and validity of the screen for child anxiety related emotional disorders (SCARED) in Turkish children. Unpublished thesis 2004.

II. Lebeau RT, Glenn DE, Hanover LN, Beesdo-Baum K, Wiitchen HU, Craske MG. A dimensional approach to measuring anxiety for DSM-5. Int J Methods Psychiatr Res 2012; 21:258-272. [CrossRef]

12. Beesdo-Baum K, Klotsche J, Knappe S, Craske MG, Lebeau RT, Hoyer J, Strober A, Pieper L, Wiitchen HU. Psychometric Properties of the Dimensional Anxiety Scales for DSM-5 In An Unselected Sample Of German Treatment Seeking Patients. Depress Anxiety 2012; 29: I 014-1024. [CrossRef] 